\title{
Avaliação Nutricional do Grão de Ervilha Forrageira (Pisum sativum) em Dietas para Suínos em Crescimento ${ }^{1}$
}

\author{
Sérgio Luiz Vieira ${ }^{2}$, Magda Metz ${ }^{3}$, Henrique Augusto dos Santos Bartels ${ }^{4}$, \\ Alexandre de Mello Kessler ${ }^{2}$
}

\begin{abstract}
RESUMO - Dietas à base de milho e farelo de soja, contendo níveis crescentes de grão de ervilha forrageira ( 0,20 e $40 \%)$, foram formuladas com os objetivos de avaliar o valor nutricional deste grão, sub-espécie hortense, cultivar Alfetta e de determinar os valores de energia digestível e metabolizável aparentes do mesmo. Todas dietas foram fornecidas a 18 suínos machos castrados híbridos comerciais com peso médio inicial de $40 \mathrm{~kg}$. O estudo teve duração de quatro semanas, com avaliação semanal do consumo de alimento, ganho de peso e conversão alimentar dos animais. Ao mesmo tempo, foram feitas coletas de fezes e de urina excretadas para avaliação de variáveis de metabolismo. Os animais consumindo as dietas com níveis crescentes de ervilha apresentaram ganho de peso, conversão alimentar, digestibilidade e retenção de nitrogênio similares aos da dieta testemunha sem ervilha. Os valores de energia digestível e de energia metabolizável aparentes, determinados para o grão de ervilha, foram de 3.968 e de $3.723 \mathrm{kcal} / \mathrm{kg} \mathrm{MS}$, respectivamente. A avaliação das respostas deste estudo sustenta a possibilidade de inclusão do grão de ervilha forrageira em dietas para suínos em crescimento em até $40 \%$, sem prejuízo ao desempenho, quando comparadas com fórmulas tradicionais com milho e farelo de soja.
\end{abstract}

Palavras-chave: ervilha, energia digestível, energia metabolizável, digestibilidade da proteína, retenção de nitrogênio

\section{Nutritional Evaluation of Ground Pea (Pisum sativum) in Diets for Growing Pigs}

ABSTRACT - Corn and soybean meal based diets with increasing levels of ground peas, sub-species hortense cultivar Alfetta $(0,20$ and $40 \%)$, were formulated to evaluate the nutritional value of this ingredient with 18 castrated male pigs of commercial hybrids averaging $40 \mathrm{~kg}$. The study also aimed to determine the apparent digestible and metabolizable energy and nitrogen retentions of peas. A total period of four weeks was used in which body weight gain, feed intake, feed conversion and amount of feces and urine were evaluated. The results demonstrated an overall performance of animals fed diets with increasing levels of green peas similar to those fed the control diet without peas. These results were consistent with the outcome from the metabolism assay, which demonstrated digestibility and nitrogen retention similar to the control diet. Digestible and metabolizable energy values of 3,968 and 3,723 kcal/kg were calculated. Results clearly indicate the possibility of inclusion up to $40 \%$ ground peas in the growing pigs feeding, without any constraint on animal performance.

Key Words: digestible energy, metabolizable energy, nitrogen retention, pea, pigs, protein digestibility

\section{Introdução}

A ervilha forrageira (Pisum sativum) é uma leguminosa não oleaginosa que apresenta níveis de proteína bruta ao redor de $20 \%$. Esta planta tem características agronômicas apropriadas à pequena propriedade familiar, pois, além de possuir características importantes para a conservação e fertilidade do solo, é cultivada no inverno, quando muitas áreas agrícolas permanecem sem uso no sul do Brasil. Estes fatores, conjugados à ausência de fatores antinutricionais em concentrações que possam afetar negativamente o desempenho animal e o perfil bromatológico favorável, tornam a ervilha uma alternativa muito promissora para a alimentação de suínos (Bastianelli et al., 1998; Gatel \& Grosjean, 1990).

No sul do Brasil, a ervilha forrageira foi introduzida pela EMATER-RS em 1999, tendo ótima aceitação na pequena propriedade familiar, devido à possibilidade de substituição parcial do grão da soja em rações para suínos, sem a necessidade de processamento térmico. Entretanto, o uso amplo da ervilha requer ainda esclarecimentos relativos aos seus perfis protéico e energético.

As variedades de ervilha mais utilizadas na alimentação de animais não ruminantes pertencem à

\footnotetext{
${ }_{1}^{1}$ Parte da Dissertação de Mestrado da segunda autora.

2 Professor do Departamento de Zootecnia - UFRGS. E.mail: slvieira@ufrgs.br

${ }^{3}$ Aluna do Programa de Pós-Graduação em Zootecnia - UFRGS.

${ }^{4}$ Extensionista da EMATER.
} 
sub-espécie hortense, possuindo flores brancas que produzem grãos redondos livres de tanino com alto teor de amido, e baixa gordura e fibra (Bastianelli et al., 1998). A ervilha possui atividade de anti-tripsina muito baixa, em torno de $13 \%$ do valor encontrado na soja (Valdebouze et al., 1980). Dentro da sub-espécie hortense, existem muitas variedades que apresentam variação nas suas características nutricionais. Gueguen \& Barbot (1988) observaram variações nos níveis protéicos na MS entre 18 e $28 \%$, sendo estas também dependentes das condições climáticas durante o crescimento da planta. Alterações nos teores e tipo de amido das ervilhas de diferentes cultivares também existem (Grosjean \& Gatel, 1986).

A diversidade entre os cultivares não tem sido um impedimento para a utilização da ervilha forrageira para suínos. Ainda que existam pequenas alterações nas digestibilidade da proteína e da energia, estas são altas para aquelas de flores brancas. Assim, não há evidências de alterações no desempenho dos animais com níveis de inclusão de até $40 \%$ em dietas basais (Lund \& Hakansson, 1986; Hlödversson, 1987; Leterme at al., 1990). A situação modifica-se quando da utilização de cultivares da sub-espécie arvense, de flores coloridas. Estas possuem tanino em concentrações capazes de reduzir a sua digestibilidade (Griffiths, 1981). Quando comparadas às digestibilidades da proteína bruta, as cultivares de flores brancas apresentam valores em torno de $90 \%$, enquanto que para as de flores coloridas os valores médios são de 70\% (Hlödversson, 1987).

Praticamente todas informações relativas ao uso das novas variedades de ervilha em dietas para animais são oriundas de condições diferentes daquelas existentes no Brasil. O presente experimento foi realizado com o objetivo de investigar o desempenho de suínos com a inclusão de níveis crescentes do grão de ervilha forrageira em dietas para a fase de crescimento, baseadas em milho e farelo de soja. Este estudo também visou determinar os valores de energia digestível (ED) e de energia metabolizável (EM) para o grão de ervilha.

\section{Material e Métodos}

Foram utilizados 18 suínos machos castrados híbridos comerciais com peso médio inicial de $40 \mathrm{~kg}$. Para a confecção das rações experimentais, foi utilizado o grão de ervilha forrageira sub-espécie hortense, cultivar Alfetta, que apresenta flores bran- cas e sementes lisas e amarelas. Os animais foram alojados individualmente em gaiolas de estudo de metabolismo semelhantes ao modelo descrito por Pekas (1968), mas com sistema de alimentação modificado, apresentando comedouro associado ao bebedouro automático, além de tela e bandeja receptoras dos resíduos de ração e coletores de fezes e urina.

As dietas experimentais foram formuladas de forma a atender as exigências nutricionais, conforme sugestão do NRC (1998), definidas da seguinte forma: sem a inclusão do grão de ervilha (E0) e com a inclusão de 20 (E20) e 40\% (E40) de ervilha moída em formulações contendo também farelo de soja e milho. Uma quarta dieta, denominada de ENB, foi constituída de $60 \%$ de E0 e $40 \%$ do grão de ervilha, sem balanceamento nutricional, com os objetivos de estudar o metabolismo do nitrogênio e determinar a ED e a EM do grão de ervilha.

A composição química do grão de ervilha forrageira utilizada neste estudo, expressa na matéria seca (MS), e as dietas experimentais obtidas a partir de programação linear (User Friendly Feed Formulation - UFFDA, 1992) estão apresentadas nas Tabelas 1 e 2, respectivamente.

Foi adotado o delineamento experimental inteiramente ao acaso, com quatro tratamentos e cinco repetições para os tratamentos E0 e ENB e quatro para os tratamentos E20 e E40, devido à restrição no número de gaiolas metabólicas. A unidade experimental foi representada por um indivíduo alojado em cada gaiola. O perído de adaptação dos animais às gaiolas e às dietas experimentais foi de oito dias e o período experimental subseqüente, de 28 dias. Foram registrados dados de desempenho (pesagens dos animais nos dias 1, 14 e 28) e de metabolismo (quatro períodos de uma semana). O alimento foi fornecido à vontade, por se tratar de experimento conjunto de desempenho (onde o efeito dos tratamentos sobre o consumo de alimento foi uma resposta estudada) e metabolismo (Kavanah et al., 2001). Isto foi possível pela existência de bebedouros automáticos nas gaiolas, permitindo a presença constante de ração nos cochos, diferindo assim das gaiolas tradicionais, em que água e ração foram fornecidas no mesmo cocho e limitaram o tempo das refeições e a ingestão diária voluntária de alimento pelos animais. As rações experimentais foram fornecidas em duas refeições ( 8 e $18 \mathrm{~h}$ ). As quantidades oferecidas diariamente basearam-se no consumo do dia imediatamente anterior e foram alocadas de forma a evitar qualquer limitação no consumo. As 
Tabela 1 - Perfil nutricional do grão de ervilha forrageira, $\% \mathrm{MS}^{*}$

Table 1 - Nutritional profile of ground pea meal, \% DM*

Nutrientes
Nutrients

Matéria seca

85,83

Dry matter

Proteína bruta

22,77

Crude protein

Energia bruta, kcal/kg

Gross energy, kcal/kg

Extrato etéreo

1,85

Ether extract

Fibra bruta

5,57

Crude fiber

Cinzas

Ash

Extrativos não nitrogenados

Nitrogen free extract

Cálcio

0,07

Calcium

Fósforo total

0,47

Total phosphorus

Lisina

1,57

Lysine

Treonina

0,82

Threonine

Metionina

Methionine

Cistina

Cystine

Metionina + Cistina

Methionine + Cystine

Alanina

Alanine

Arginina

Arginine

Ácido aspártico

0,19

0,32

0,51

0,98

1,77

Aspartic acid

Ácido glutâmico $\quad 3,45$

Glutamic acid

Glicina

Glycine

Histidina

Histidine

Isoleucina

Isoleucine

Leucina

Leucine

Fenilalanina

Phenylalanine

Serina

Serine

Tirosina

Tyrosine

Valina

Valine

Triptofano

Tryptophan

* A determinação de aminoácidos foi efetuada pela Ajinomoto Biolatina Ind. e Com. Ltda. As demais análises foram realizadas no Laboratório de Nutrição Animal da UFRGS, Porto Alegre, RS.

* Amino acids were determined by Ajinomoto Biolatina Ind. \& Com. Ltda. All other analyses were performed at the Animal Nutrition Laboratory, UFRGS, Porto Alegre, RS. sobras foram coletadas em tela e bandeja ajustadas sob o comedouro, retornando para o mesmo ao início de cada refeição. No final de uma semana, as sobras foram recolhidas e pesadas. Estas, após determinação da MS foram utilizadas para corrigir o consumo de alimento.

As fezes totais semanais foram coletadas de acordo com a técnica descrita por Morgan et al. (1975), acrescentando-se $1 \%$ de óxido férrico às rações da primeira refeição do período experimental, bem como à primeira refeição do sexto dia de cada período. Amostras com peso médio de 250 gramas foram secas por 72 horas em estufa a $60^{\circ} \mathrm{C}$, sendo pesadas e moídas em seguida. Procedimento similar foi realizado com amostras de $100 \mathrm{~mL}$ de urina submetidas à análise para determinação de nitrogênio (AOAC, 1975) e de energia bruta, utilizando bomba calorimétrica.

Os valores de ED e EM das dietas experimentais e da ervilha foram calculados de acordo com Matterson et al. (1965), utilizando-se os valores de EB das dietas E0 e ENB e das fezes correspondentes ao consumo das mesmas. Foi utilizado o valor de $9,17 \mathrm{kcal} / \mathrm{g}$ de nitrogênio urinário para o cálculo da EM (Morgan et al., 1975).

A análise estatística foi efetuada com o uso do Software Statistical Analyses System - SAS (1985), com o procedimento GLM. Para comparação de médias foi usado o teste de Tukey.

\section{Resultados e Discussão}

Os animais consumindo as diversas dietas experimentais não apresentaram diferenças significativas entre si para nenhuma das medidas de desempenho realizadas $(\mathrm{P}>0,05)$, o que pode ser visualizado na Tabela 3. Vários estudos com uso de ervilha em dietas para suínos têm sido realizados principalmente na Europa e Canadá, apresentando resultados favoráveis à sua inclusão em dietas para suínos em crescimento (Lund \& Hakansson, 1986; Edwards et al. 1987; Goodlad \& Matters, 1991). Neste experimento, a avaliação do uso da ervilha como ingrediente em dietas para suínos foi feita seguindo inclusões de níveis crescentes de ervilha em dietas nutricionalmente balanceadas com a suplementação de gordura e aminoácidos. Foi possível observar que os animais não tiveram o crescimento afetado ou piora na conversão alimentar em nenhum dos níveis de inclusão de ervilha, quando comparado ao desempenho obtido com a dieta controle. Os resultados indicam que é possível incluir até $40 \%$ desta leguminosa em dietas

R. Bras. Zootec., v.32, n.6, p.1705-1712, 2003 (Supl. 1) 
Tabela 2 - Composição das dietas experimentais

Table 2 - Composition of the experimental diets

Ingredientes, \%

Dietas experimentais

Ingredients, $\%$

Experimental diets

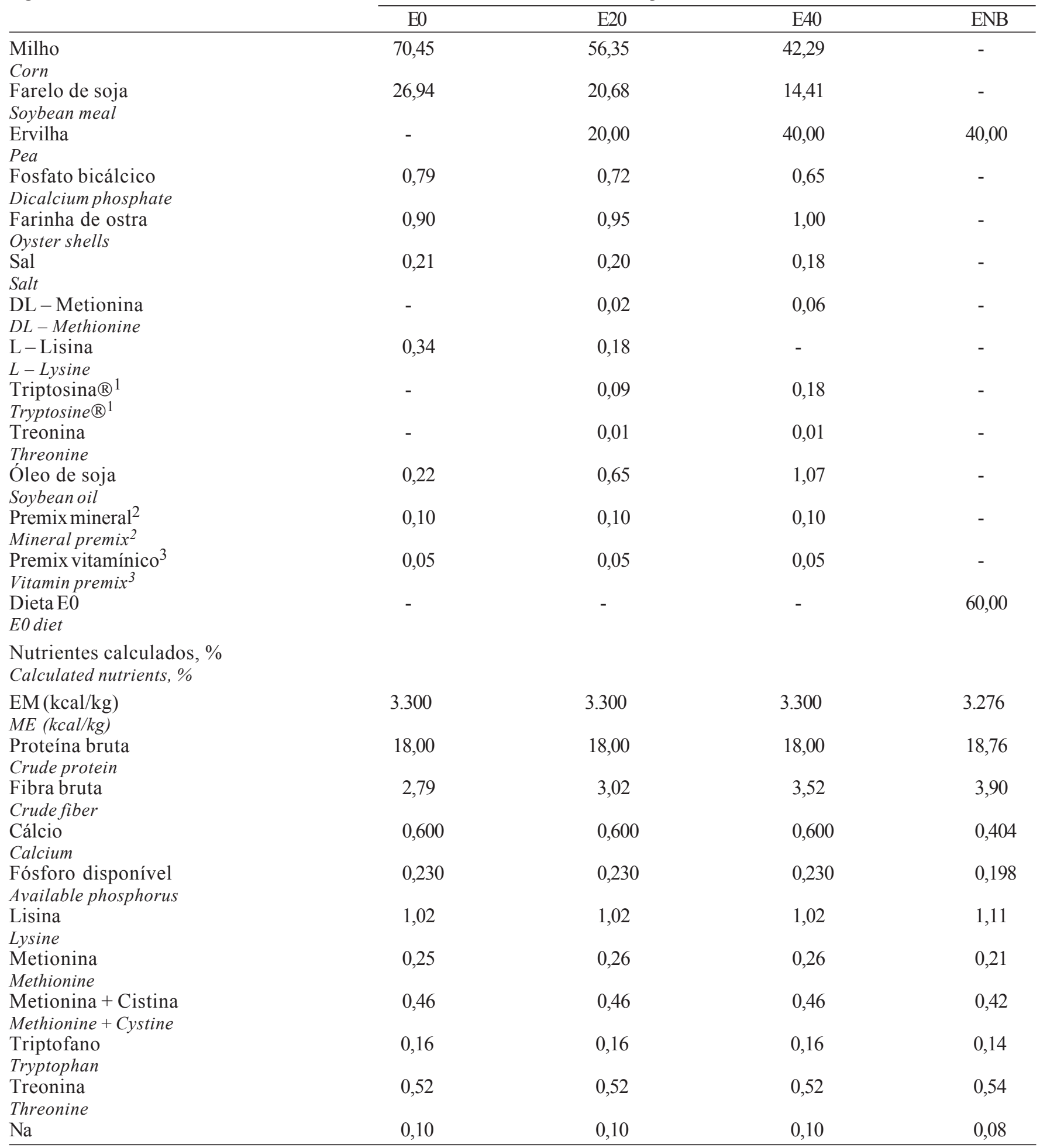

${ }^{1}$ Marca comercial de Archer Daniels Midland Company, IL., EUA, contendo 15\% de Triptofano, 55,3\% de Lisina, 1,75\% de Metionina, $0,15 \%$ de Treonina e $0,5 \%$ de Valina.

2 Composição por kg de ração: $\mathrm{Fe}=60 \mathrm{mg} ; \mathrm{Zn}=100 \mathrm{mg} ; \mathrm{Mn}=40 \mathrm{mg} ; \mathrm{Cu}=10 \mathrm{mg} ; \mathrm{I}=0,4 \mathrm{mg} ; \mathrm{Se}=0,3 \mathrm{mg}$.

${ }^{3}$ Composição por kg de ração: vit. $A=5000 \mathrm{UI}$; vit. $D_{3}=1000 \mathrm{UI}$; vit. $E=15 \mathrm{mg}$; vit. $\mathrm{K}_{3}=1,2 \mathrm{mg} ;$ vit. $B_{2}=4,2 \mathrm{mg} ;$ vit. $B_{6}=1,1 \mathrm{mg}$; vit. $B_{12}=0,015 \mathrm{mg}$; ácido pantotênico $=14 \mathrm{mg}$; niacina $=23 \mathrm{mg}$; ácido fólico = 0,6 mg; biotina = 0,05 mg.

1 Produced by Archel Daniels Midland Company, IL, USA, guaranteed 15\% Tryptophan, 55.3\% Lysine, 1.75\% Methionine, .15\% Threonine, and .5\% Valine.

${ }^{2}$ Composition per $\mathrm{kg}$ of feed: $\mathrm{Fe}=60 \mathrm{mg} ; \mathrm{Zn}=100 \mathrm{mg} ; \mathrm{Mn}=40 \mathrm{mg} ; \mathrm{Cu}=10 \mathrm{mg} ; \mathrm{I}=.4 \mathrm{mg} ; \mathrm{Se}=.3 \mathrm{mg}$.

${ }^{3}$ Composition per kg of feed: vit. $A=5000 \mathrm{Ul}$; vit. $D_{3}=1000 \mathrm{UI}$; vit. $E=15 \mathrm{mg}$; vit. $K_{3}=1.2 \mathrm{mg}$; vit. $B_{2}=4.2 \mathrm{mg}$; vit. $B_{6}=1.1 \mathrm{mg} ;$ vit. $B_{12}=.015 \mathrm{mg} ;$ panthotenic acid $=14 \mathrm{mg} ;$ niacin $=23 \mathrm{mg} ;$ folic acid $=.6 \mathrm{mg} ;$ biotin $=.05 \mathrm{mg}$. 
para suínos na fase de crescimento, desde que estas sejam balanceadas para os mesmos nutrientes.

Os coeficientes de digestibilidade aparente da matéria seca (CDMS), da proteína bruta (CDPB), da energia bruta (CDEB), de retenção do nitrogênio
(CRN) e o nitrogênio retido (NR) estão apresentados na Tabela 4. A inclusão de até $40 \%$ de ervilha às rações manteve a mesma qualidade da dieta quanto à digestibilidade da matéria seca e da energia $(\mathrm{P}>0,05)$. A possibilidade de formular rações com

Tabela 3 - Desempenho de suínos em crescimento alimentados com dietas contendo níveis crescentes de ervilha forrageira *

Table 3 - Performance of growing pigs fed diets with increasing levels of ground peas

\begin{tabular}{|c|c|c|c|c|c|}
\hline \multirow[b]{2}{*}{$\begin{array}{l}\text { Variável } \\
\text { Variable } \\
\end{array}$} & \multirow[b]{2}{*}{$\begin{array}{l}\text { Período, dias } \\
\text { Period, days }\end{array}$} & \multicolumn{3}{|c|}{$\begin{array}{c}\text { Ração experimental } \\
\text { Experimental diet }\end{array}$} & \multirow[b]{2}{*}{ Prob. } \\
\hline & & $\begin{array}{c}\text { E0 } \\
\text { Prob. }\end{array}$ & E20 & $\mathrm{E} 40$ & \\
\hline Ganho de peso (g/dia) & $1-14$ & $900 \pm 56$ & $905 \pm 34$ & $800 \pm 64$ & 0,38 \\
\hline Weight gain $(g / d)$ & $\begin{array}{c}15-28 \\
1-28\end{array}$ & $\begin{array}{l}843 \pm 31 \\
871 \pm 64\end{array}$ & $\begin{array}{l}819 \pm 75 \\
862 \pm 54\end{array}$ & $\begin{array}{l}907 \pm 59 \\
853 \pm 70\end{array}$ & $\begin{array}{l}0,77 \\
0,57\end{array}$ \\
\hline Consumo de ração (g/dia) & $1-14$ & $2187 \pm 68$ & $2126 \pm 111$ & $2129 \pm 74$ & 0,33 \\
\hline Feed consumption $(\mathrm{g} / \mathrm{d})$ & $\begin{array}{c}15-28 \\
1-28\end{array}$ & $\begin{array}{l}2492 \pm 51 \\
2339 \pm 89\end{array}$ & $\begin{array}{l}2389 \pm 209 \\
2257 \pm 193\end{array}$ & $\begin{array}{l}2445 \pm 107 \\
2287 \pm 160\end{array}$ & $\begin{array}{l}0,36 \\
0,34\end{array}$ \\
\hline $\begin{array}{l}\text { Conversão alimentar } \\
\text { Conversion (Feed/gain) }\end{array}$ & $\begin{array}{c}1-14 \\
15-28 \\
1-28\end{array}$ & $\begin{array}{l}2,46 \pm 0,15 \\
2,98 \pm 0,15 \\
2,69 \pm 0,17\end{array}$ & $\begin{array}{l}2,35 \pm 0,07 \\
2,92 \pm 0,20 \\
2,64 \pm 0,14\end{array}$ & $\begin{array}{l}2,69 \pm 0,14 \\
2,72 \pm 0,17 \\
2,68 \pm 0,20\end{array}$ & $\begin{array}{l}0,42 \\
0,44 \\
0,43\end{array}$ \\
\hline
\end{tabular}

* Valores são médias seguidas do erro-padrão para o tratamento.

*Values are treatment means followed by their standard error.

Tabela 4 - Coeficientes de digestibilidade aparente da matéria seca (CDMS), proteína bruta (CDPB), energia bruta (CDEB), coeficiente de retenção do nitrogênio (CRN) e nitrogênio retido (NR) de dietas contendo níveis crescentes de grão de ervilha forrageira oferecidas para suínos em crescimento*

Table 4 - Dry matter (CDMS), crude protein (CDPB), crude energy (CDEB) apparent digestibility coefficients, coefficient of nitrogen retention (CRN), and retained nitrogen (NR) of diets with increasing levels of ground peas fed to growing pigs*

\begin{tabular}{|c|c|c|c|c|c|}
\hline \multirow[b]{2}{*}{$\begin{array}{l}\text { Variável } \\
\text { Variable }\end{array}$} & \multirow[b]{2}{*}{$\begin{array}{l}\text { Período, dias } \\
\text { Period, day }\end{array}$} & \multicolumn{3}{|c|}{$\begin{array}{l}\text { Ração experimental } \\
\text { Experimental diets }\end{array}$} & \multirow[b]{2}{*}{ Prob. } \\
\hline & & $\mathrm{E} 0$ & E20 & $\mathrm{E} 40$ & \\
\hline \multirow[t]{4}{*}{ CDMS (\%) } & $1-7$ & $90,9 \pm 2,0$ & $88,2 \pm 1,5$ & $88,6 \pm 2,2$ & 0,148 \\
\hline & $8-14$ & $88,6 \pm 1,3$ & $87,8 \pm 1,1$ & $87,7 \pm 2,1$ & 0,668 \\
\hline & $15-21$ & $89,7 \pm 1,5$ & $89,7 \pm 0,6$ & $89,5 \pm 1,3$ & 0,981 \\
\hline & $22-28$ & $89,8 \pm 0,7$ & $89,9 \pm 1,1$ & $90,0 \pm 1,7$ & 0,986 \\
\hline \multirow[t]{4}{*}{ CDPB $(\%)$} & $1-7$ & $89,3 \pm 2,5$ & $85,1 \pm 3,1$ & $86,0 \pm 1,1$ & 0,057 \\
\hline & $8-14$ & $87,4^{\mathrm{a}} \pm 1,9$ & $83,9^{b} \pm 3,0$ & $84,4^{\mathrm{ab}} \pm 1,8$ & 0,031 \\
\hline & $15-21$ & $89,0 \pm 2,2$ & $87,9 \pm 0,9$ & $88,0 \pm 2,0$ & 0,689 \\
\hline & $22-28$ & $89,0 \pm 1,0$ & $88,4 \pm 1,3$ & $87,5 \pm 0,9$ & 0,149 \\
\hline \multirow[t]{4}{*}{ CDEB(\%) } & $1-7$ & $90,4 \pm 2,3$ & $87,0 \pm 1,7$ & $87,0 \pm 0,7$ & 0,064 \\
\hline & $8-14$ & $87,6 \pm 1,2$ & $86,7 \pm 1,4$ & $86,7 \pm 1,1$ & 0,434 \\
\hline & $15-21$ & $88,8 \pm 1,7$ & $88,8 \pm 0,5$ & $89,0 \pm 1,1$ & 0,947 \\
\hline & $22-28$ & $89,2 \pm 0,7$ & $89,1 \pm 1,3$ & $89,4 \pm 1,1$ & 0,958 \\
\hline \multirow[t]{4}{*}{ CRN(\%) } & $1-7$ & $29,8^{b} \pm 5,8$ & $38,9^{\mathrm{ab}} \pm 11,5$ & $49,3^{a} \pm 2,1$ & 0,006 \\
\hline & $8-14$ & $38,2 \pm 8,5$ & $47,6 \pm 9,21$ & $40,7 \pm 7,6$ & 0,348 \\
\hline & $15-21$ & $43,2 \pm 8,1$ & $47,3 \pm 5,3$ & $49,7 \pm 1,7$ & 0,300 \\
\hline & $22-28$ & $43,3 \pm 9,6$ & $53,3 \pm 13,8$ & $45,2 \pm 9,0$ & 0,410 \\
\hline \multirow[t]{4}{*}{ RN (g) } & $1-7$ & $109^{b} \pm 23,7$ & $143^{\mathrm{ab}} \pm 32,1$ & $190^{\mathrm{a}} \pm 16,8$ & 0,002 \\
\hline & $8-14$ & $185 \pm 42,3$ & $227 \pm 37,1$ & $198 \pm 38,1$ & 0,377 \\
\hline & $15-21$ & $211 \pm 43,2$ & $235 \pm 12,5$ & $246 \pm 15,8$ & 0,267 \\
\hline & $22-28$ & $208 \pm 46,4$ & $242 \pm 33,0$ & $229 \pm 42,5$ & 0,534 \\
\hline
\end{tabular}

*Valores são médias seguidas do erro-padrão para o tratamento.

*Values are treatment means followed by their standard error. 
altos níveis de ervilha, sem afetar a digestibilidade da matéria seca das mesmas, tem importância que extrapola o desempenho econômico da criação, uma vez que não representa aumento no volume das excretas.

Nos vários períodos do experimento, o NR foi similar entre todas as dietas com exceção da primeira semana quando o $\mathrm{CRN}$ dos animais alimentados com a dieta controle foi inferior aos alimentados com aquela contendo $40 \%$ de ervilha $(\mathrm{P}<0,01)$. Estes resultados são similares aos relatados por Hlödversson (1987), que apresentaram perfíl protéico favorável à ervilha.

O CDPB foi ligeiramente superior para a dieta controle na segunda semana do experimento $(\mathrm{P}<0,05)$ não diferindo nas demais fases. Leterme et al. (1990) e Hlödversson (1987) obtiveram respostas semelhantes quando incluiram 35 e $40 \%$ de ervilha pertencentes à variedades distintas. Os valores obtidos após análise da atividade ureática e da concentração de tanino na ervilha do presente experimento foram baixos ( $\mathrm{D} \mathrm{pH}<0,05$; taninos totais $<0,05 \%$ ) e não justificam as alterações de digestibilidade observadas. A inclusão da ervilha nas rações experimentais não alterou o teor de fibra das dietas e, portanto, não explica a menor digestibilidade que ocorreu em apenas uma semana. Trabalhos de investigação recentes com o uso da ervilha não sugerem a presença de outros fatores anti-nutricionais em concentrações que poderiam ocasionar prejuízo à digestibilidade deste grão (Leterme et al., 1990).

Não foi observada diferença significativa entre as dietas em nenhum dos períodos experimentais para a digestibilidade da energia (Tabela 4). Os resultados de estudos usando grãos de ervilha na alimentação de suínos mostram que as diferenças no perfil de nutrientes e na capacidade de utilização da dieta variam entre as diversas cultivares de ervilha disponíveis. As diferenças mais significativas são encontradas entre as cultivares de flores brancas e coloridas. Segundo Leterme at al. (1990), as de flores brancas são mais digestíveis, pois possuem menos tanino e têm menor variabilidade protéica. Estes autores verificaram que as características vantajosas de duas variedades de flores brancas permitiram até $40 \%$ de inclusão em rações para suínos em crescimento sem prejuízo ao desempenho animal. Estudos conduzidos por Hlödversson (1987) e Goodlad \& Matters (1991) ratificaram a maior digestibilidade destas cultivares, quando comparadas às de flores coloridas.

Constam na Tabela 5 os valores relativos à digestibilidade e metabolizabilidade das dietas com ervilha. É possível observar que a inclusão de ervilha até o nível de $40 \%$ não afetou os valores de ED e EM das dietas $(\mathrm{P}<0,05)$. Resultados similares foram obtidos por Lund \& Hakansson (1986), com a inclusão de $30 \%$ de ervilha de flores brancas na dieta de suínos em crescimento.

$\mathrm{Na}$ Tabela 6, estão apresentados os valores médios dos coeficientes de digestibilidade e os valores de energia digestível e metabolizável para o grão de ervilha utilizado neste estudo. As médias foram favoráveis ao uso da ervilha devido à digestibilidade da matéria seca (em torno de 90\%), similar ao milho e farelo de soja (Embrapa, 1991). Os valores de ED e

Tabela 5 - Energia digestível (ED) e metabolizável (EM) aparentes de dietas contendo níveis crescentes de ervilha forrageira oferecidas para suínos em crescimento, $\mathrm{kcal} / \mathrm{kg} \mathrm{MS}^{*}$

Table 5 - Apparent digestible (ED) and metabolizable (EM) energy values of diets with increased levels of peas fed to growing pigs, $\mathrm{kcal} / \mathrm{kg} \mathrm{DM}$ *

\begin{tabular}{lccccc}
\hline & & \multicolumn{3}{c}{$\begin{array}{c}\text { Dietas experimentais } \\
\text { Experimental diets }\end{array}$} \\
\cline { 3 - 6 } $\begin{array}{l}\text { Variável } \\
\text { Variable }\end{array}$ & $\begin{array}{c}\text { Período, dias } \\
\text { Period, day }\end{array}$ & E0 & E20 & E40 & Prob. \\
\hline ED & $1-7$ & $3826 \pm 96$ & $3681 \pm 74$ & $3738 \pm 30$ & 0,064 \\
& $8-14$ & $3710 \pm 51$ & $3668 \pm 60$ & $3670 \pm 46$ & 0,434 \\
& $15-21$ & $3762 \pm 71$ & $3758 \pm 21$ & $3771 \pm 48$ & 0,947 \\
EM & $22-28$ & $3776 \pm 31$ & $3774 \pm 56$ & $3783 \pm 46$ & 0,958 \\
& $1-7$ & $3656 \pm 90$ & $3544 \pm 78$ & $3627 \pm 30$ & 0,153 \\
& $8-14$ & $3569 \pm 59$ & $3561 \pm 77$ & $3538 \pm 52$ & 0,742 \\
& $15-21$ & $3631 \pm 62$ & $3634 \pm 15$ & $3655 \pm 38$ & 0,747 \\
& $22-28$ & $3646 \pm 32$ & $3670 \pm 72$ & $3655 \pm 37$ & 0,774 \\
\hline
\end{tabular}

* Valores na Tabela são médias seguidas do erro-padrão para o tratamento.

* Values are treatment means followed by their standard error.

R. Bras. Zootec., v.32, n.6, p.1705-1712, 2003 (Supl. 1) 
Tabela 6 - Coeficientes de digestibilidade aparente da matéria seca (CDMS), proteína bruta (CDPB), energia bruta (CDEB) e energia digestível (ED), coeficiente de metabolizabilidade da energia bruta (CMEB) e valor de energia metabolizável (EM) do grão de ervilha na MS para suínos em crescimento

Table 6 - Coefficients of apparent digestibily of dry matter (CDMS), crude protein (CDPB), gross energy (CDEB), digestible energy (ED), coefficient of metabolizability of gross energy (CMEB) and dry matter metabolizable energy value (EM) of ground peas fed to growing pigs

\begin{tabular}{lcccccc}
\hline & CDMS, $\%$ & CDPB, $\%$ & CDEB, $\%$ & ED, $\mathrm{kcal} / \mathrm{kg} \mathrm{MS}$ & CMEB, $\%$ & EM, $\mathrm{kcal} / \mathrm{kg}$ \\
\hline $\begin{array}{l}\text { Média } \\
\text { Mean }\end{array}$ & 90,8 & 84,0 & 89,6 & 3968 & 86,4 & 3723 \\
DP & 3,6 & 4,2 & 2,5 & 109,0 & 2,9 & 89 \\
SD & & & & & & \\
\hline
\end{tabular}

EM obtidos para a ervilha $(3.968$ e $3.723 \mathrm{kcal} / \mathrm{kg}$, respectivamente) são similares aos do milho. Considerando o valor três vezes superior ao da proteína bruta do milho e perfil de aminoácidos superior, a ervilha apresenta-se como alternativa viável na alimentação de suínos em crescimento com redução de custo de produção. Estas características são muito importantes para a propriedade familiar que usualmente cultiva a maior parte dos grãos, usados em rações para suínos, dentro da propriedade.

A ervilha utilizada no presente experimento apresentou valor de proteína bruta de $22,8 \%$ na MS. Este resultado representa um valor intermediário àquele apresentado na literatura (Gueguen \& Bardot, 1988; Grosjean et al., 1999; Bastianelli et al., 1998). A variabilidade entre os valores nutricionais de diferentes cultivares de ervilha pode ser grande e, portanto, é necessário conhecer as diferenças entre as mesmas antes de proceder à formulações de rações.

As medidas da atividade ureática da ervilha forrageira efetuadas neste experimento apresentaram valor médio de $0,02 \mathrm{DpH}$, valor baixo quando comparado aos padrões exigidos para a desativação de fatores anti-tripsina em grão de soja, geralmente até $0,20 \mathrm{DpH}$. A concentração de tanino na ervilha deste estudo foi de $0,06 \%$, insuficiente para prejudicar o desempenho animal.

Hlödversson (1987) determinou valores de energia digestível para o grão de ervilha variando de 3752 a $3920 \mathrm{kcal} / \mathrm{kg}$ MS, Fan \& Sauer (1994) encontraram valores que variaram entre 3346 e $3442 \mathrm{kcal} / \mathrm{kg} \mathrm{MS}$, enquanto Grosjean et al. (1998) encontraram valor de $3905 \mathrm{kcal} / \mathrm{kg}$ MS. Os resultados revisados apresentaram valores de EM em torno de 5\% abaixo da ED, diferença correspondente a perdas urinárias esperadas em dietas produzidas com milho e farelo de soja segundo o NRC (1998). No presente estudo, a menor diferença foi de $6,17 \%$ para a EM.

\section{Conclusões}

O grão de ervilha, sub-espécie hortense, cultivar Alfetta, é uma alternativa viável na alimentação de suínos em fase de crescimento. A inclusão deste grão até o nível de $40 \%$ não prejudica o desempenho animal. $\mathrm{Na}$ formulação de rações com ervilha para suínos desta categoria, são sugeridos valores de energia digestível e metabolizável aparentes de 3.968 e $3.723 \mathrm{kcal}$ por $\mathrm{kg}$ de matéria seca, respectivamente.

\section{Literatura Citada}

ASSOCIATION OF OFFICIAL ANALITICAL CHEMISTS AOAC. Official methods of analysis. 12.ed. Washington, D.C.: 1975. 1094p.

BASTIANELLI, D.; GROSJEAN, F.; PERYRONNET, M. et al. Feeding value of pea (Pisum sativum, L.) 1. Chemical composition of different categories of peas. Animal Science, v.67, n.3, p.609-619, 1998.

EDWARDS, S.A.; LEWIS, D.S.R.; FAIRBAIRN, C.B. The effects of pea variety and inclusion rate in the diet on the performance of finishing pigs. Journal of Agricultural Science, v.108, p.383-388, 1987.

EMPRESA BRASILEIRA DE PESQUISA AGROPECUÁRIA EMBRAPA. Tabela de composição química e valores energéticos de alimentos para suínos e aves. 3.ed. Concórdia: 1991. 97p.

FAN, M.Z.; SAUER, W.C. Amino acid and energy digestibility in peas (Pisum sativum) from white-flowers spring cultivars for growing pigs. Journal of the Science of Food and Agriculture, v.64, p.249-256, 1994.

GATEL, F.; GROSJEAN, F. Composition and nutritive value of peas for pigs: a review of European results. Livestock Production Science, v.26, p.155-175, 1990.

GOODLAD, B.J.S.; MATHERS, J.C. Digestion by non-starch polysaccharides in wheat and raw peas (Pisum sativum) fed in mixed diets. British Journal of Nutrition, v.65, p.259270, 1991.

GRIFFITHS, D.W. The polyphenolic content and enzyme inhibitory activity of testas from beans (Vicia faba) and peas (Pisum spp.) varieties. Journal of the Science of Food and Agriculture, v. 32, p.797-804, 1981.

Grosjean, F.; GATEL, F. Peas for pigs. Pig News and Information, v.7., n.4, p.443-448, 1986. 
GROSJEAN, F.; BASTIANELLI, D.; BOURDILLON, A. et al. Feeding value of pea (Pisum sativum, L.). 2. Nutritional value in pig. Animal Science, v.67, p.621-625, 1998.

GROSJEAN, F.; BARRIER-GUILLOT, B.; BASTIANELLI, D. et al. Feeding value of pea (Pisum sativum, L.) for poultry. Animal Science, v.69, p.591-599, 1999.

GUEGUEN, J.; BARDOT, J. Quantitative and qualitative variability of peas (Pisum sativum, L.) protein composition. Journal of the Science of Food and Agriculture, v.42, p.209-224, 1988.

HLÖDVERSSON, R. The Nutritive value of white- and darkflowered cultivars of pea for growing-finishing pigs. Animal Feed Science and Technology, v.17, p.245-255, 1987.

KAVANAGH, S.; LYNCH, P.B.; MARA, F.O. et al. A comparison of total collection and marker technique for the measurement of apparent digestibility of diets for growing pigs. Animal Feed Science and Technology, v.89, p.49-58, 2001.

LETERME, P.; BECKERS, Y.; THEWIS, A. Trypsin inhibitors in peas: varietal effect and influence on digestibility of crude protein by growing pigs. Animal Feed Science and Technology, v.29, p.45-55, 1990.

LUND, S.; HÅKANSSON, J. Nutritional and growth studies with pea-crop meals and peas for growing-finishing pigs. Animal Feed Science and Technology, v.16, p.119-128, 1986.

MATTERSON, L.D.; POTTER, L.M.; STUTZ, N.W. et al. The metabolizable energy of feed ingredients for chickens. University of Connecticut Research Report, v.7, p.3-11, 1965 .
MORGAN, D.J.; COLE, D.J.A.; LEWIS, D. Energy values in pig nutrition. I. The relationship between digestible energy, metabolizable energy and total digestible nutrient values of a range of feedstuffs. Journal of Agricultural Science, v. 84, p.7-17, 1975.

NATIONAL RESEARCH COUNCIL - NRC. Nutrient requirements of swine. 10.ed. Washington, D.C.: 1998. $189 \mathrm{p}$.

PEKAS, J.C. Versatile swine laboratory apparatus for physiologic and metabolic studies. Journal of Animal Science, v.27, p.1303-1306. 1968.

SAS INSTITUTE. SAS user's guide: Statistics. 5.ed. Cary, N.C., 1985. 956p.

SLINKARD, A.E. Composición nutricional de la arveja forrajera. Guía de La Industria Forrajera. Canada: Instituto Canadense Internacional de Granos. 2.ed. p.5-8, 1997.

USER FRIENDLY FEED FORMULATION - UFFDA. Georgia: University of Georgia, 1992.

VALDEBOUZE, P.; BERGERON, E.; GABORIT, T. et al. Content and distribution of trypsin inhibitors and hemoglutinins in some legume seeds. Canadian Journal of Plant Science, v.60, p.695-701, 1980.

Recebido em: 20/10/01

Aceito em: 08/07/03 